\title{
Post-publication peer review in biomedical journals: overcoming obstacles and disincentives to knowledge sharing
}

\author{
Karen Shashok*, Valerie Matarese ${ }^{* *}$
}

\begin{abstract}
The importance of post-publication peer review (PPPR) as a type of knowledge exchange has been emphasized by several authorities in research publishing, yet biomedical journals do not always facilitate this type of publication. Here we report our experience publishing a commentary intended to offer constructive feedback on a previously published article. We found that publishing our comment required more time and effort than foreseen, because of obstacles encountered at some journals. Using our professional experience as authors' editors and our knowledge of publication policies as a starting point, we reflect on the probable reasons behind these obstacles, and suggest ways in which journals could make PPPR easier. In addition, we argue that PPPR should be more explicitly valued and rewarded in biomedical disciplines, and suggest how these publications could be included in research evaluations. Eliminating obstacles and disincentives to PPPR is essential in light of the key roles of post-publication analysis and commentary in drawing attention to shortcomings in published articles that were overlooked during pre-publication peer review.
\end{abstract}

Keywords: article processing charge, commentary, correspondence, editorial policies, instructions to authors, incentives, letter to the editor, open access, post-publication peer review, research evaluation criteria

\section{Introduction}

Editorial peer review is considered the most important form of research evaluation, yet its flaws are well known (Wager and Jefferson 2001; Smith 2006; Tennant et al. 2017). Journal editors, in theory, make their own informed decisions about manuscript acceptance taking into account the comments of external reviewers, but may rely predominantly or solely on reviewers' feedback without exerting

\footnotetext{
*Translator and Editorial Consultant, 18008 Granada, Spain, kshashok@kshashok.com

**A Authors' Editor and Editorial Consultant, 31020 Vidor (TV), Italy (Corresponding author) vmatarese@uptoit.org
} 
true editorial oversight. In many cases, acceptance of a manuscript for publication in biomedical journals is based on the views of two or three individuals, who may lack the knowledge and skills to provide a rigorous evaluation (Belluz and Hoffman 2018; Huang 2013; Shashok 2008). As a result, many published research articles contain ambiguities, errors, or flaws that undermine the conclusions of the study and may require retraction.

It has long been recognized that peer review does not stop at publication. Rather, as Poole wrote in 1996, "Publication lies much closer to the beginning than to the end of peer review. ... [T] he postpublication phase is the most important phase of peer review. Publication merely signifies that one's work is deemed worthy of widespread critical scrutiny" (Poole 1996). The view that real peer review begins after publication has been echoed many times (Liesegang 2010; Smith 2011; Hames 2013; Ross-Hellauer 2016; Tennant 2017). Peer review after publication "forms an essential part of the recognition that research is a continuously evolving process built upon discretised 'discoveries' published as research papers” (Tennant 2017). Here we define post-publication peer review (PPPR) as readers' comments on articles published in journals that use pre-publication peer review, although other definitions exist (Ross-Hellauer 2016).

Because PPPR helps advance knowledge, biomedical journals are encouraged to publish readers' comments on previously published articles. According to the Committee on Publication Ethics, "Journals must allow debate post publication either on their site, through letters to the editor, or on an external moderated site, such as PubPeer" (https://publicationethics.org/postpublication). The International Committee of Medical Journal Editors recommends that "Medical journals should provide readers with a mechanism for submitting comments, questions, or criticisms about published articles, usually but not necessarily always through a correspondence section or online forum" (http://www.icmje.org/recommendations/browse/publishing-and-editorial-

issues/correspondence.html). The World Association of Medical Editors (WAME) advises journal editors to "Promote self-correction in science and participate in efforts to improve the practice of scientific investigation by publishing corrections, retractions, and critiques of published articles" (http://www.wame.org/policy-statements). WAME further recommends that "All journals should have space in which published work can be questioned, and errors pointed out" (http://www.wame.org/about/syllabus-for-prospective-and-newly-appointed). These views are echoed in the $A M A$ Manual of Style, which also advises that "Electronic journals should link from articles to the letters related to them to facilitate retrieval" (Iverson et al. 2009). A recent consensus statement on core competences for biomedical journal editors proposed that they should "help ensure the opportunity for ... post-publication criticisms of research" (Moher et al. 2017). Unfortunately, these editorial policy and practice recommendations are not implemented by all biomedical journals (see, for example, PLOS Medicine Editors 2013; Ghanbari and Derakhshan Rad 2015; Winker 2015; Goldacre 2016; Allison et al. 2016).

We recently published a 1000-word commentary (Matarese and Shashok 2018) on the consensus statement cited above (Moher et al. 2017), and found the publication process - summarized below to be considerably more arduous than expected. The aims of this article are to illustrate the obstacles we overcame to publish a PPPR comment, and then reflect on how some current editorial practices 
and research evaluation policies may act as disincentives to PPPR. To conclude, we suggest how stakeholders in research dissemination and evaluation could lower some barriers to PPPR, to the benefit of both research evaluation and the advancement of science.

\section{Case description}

An international team of 30 stakeholders in biomedical publishing developed a consensus statement on core competencies for editors of biomedical journals (Moher et al. 2017). We read the article from our professional viewpoint as authors' editors (https:/ / en.wikipedia.org/wiki/Author_editing; Tacker 1980; Eastwood 1981; Shashok 2001; Burrough-Boenisch 2013; Matarese 2016) and from that of our clients - biomedical researchers based mostly in Spain and Italy, whom we regularly help deal with journal submissions. Believing that the consensus statement had important omissions (e.g. ensuring that authors receive useful feedback on the language and writing, and dealing effectively with inappropriate text re-use and plagiarism), we wrote a response to call attention to these issues (Matarese and Shashok 2018).

\section{First venue}

Our first choice for publication was logically BMC Medicine, the journal that published the article we commented on. The instructions for authors indicated that our manuscript should be submitted to their Correspondence section, where manuscripts require an initial inquiry and approval from the editorial staff prior to submission (https://bmcmedicine.biomedcentral.com/submissionguidelines/preparing-your-manuscript/correspondence). To prepare our inquiry letter, we obtained the name of the editor-in-chief from the journal's website and searched for information about her so as to personalize our inquiry email. We discovered that she no longer held this position (indeed the job vacancy had been announced months earlier). We then focused on the deputy editor, but our investigations disclosed that she was on maternity leave, leaving us to wonder to whom we should address our inquiry. In view of the inaccurate information on the journal's website, and despite our misgivings, we addressed our inquiry to the "Editorial Team". Our letter explained that we wished to comment on a published article, and included the reference to that article, title and abstract of our submission, keywords and our short biostatements.

To our surprise, the response to our initial inquiry, 6 days later, was negative:

This is an interesting topic; however, we are of the opinion that this particular article would be better suited to a specialist audience, rather than our general medical readership.

The email suggested a different journal by the same publisher. We felt this journal was unsuitable because its scope did not include the topic of the article we were commenting on, and its readership was different from our target audience. 
The email was signed by the journal's assistant editor. Although sent to the corresponding author (KS), the email was addressed to "Ms. Matarese", which was odd given that Karen's email address, which the assistant editor presumably saw, contains "kshashok" in both the mailbox name and domain name.

Disappointed, we decided to find another journal rather than appeal this decision. We assumed that the assistant editor had not paid much attention to our inquiry: she appeared to have overlooked the fact that we wished to comment on an article this journal had published, and had not addressed the corresponding author correctly in her reply. We also assumed that the alternative journal suggested had been identified by the publisher's (unhelpful, in this case) automated system rather than by a human reader familiar with the topic we discussed. These factors suggested to us that subsequent editorial processes at this journal were likely to lead to misunderstandings and lost time for everyone involved. The only positive outcome of this attempt was that only 6 days were wasted with the first journal we tried (Table 1).

Table 1. Features of three publication venues (journal or platform) approached, outcomes, and time involved

\begin{tabular}{|c|c|c|c|c|}
\hline Venue & $\begin{array}{l}\text { Article processing } \\
\text { charge }\end{array}$ & $\begin{array}{l}\text { 2-year } \\
\text { Impact } \\
\text { Factor }\end{array}$ & Outcome & $\begin{array}{l}\text { Approximate } \\
\text { time spent } \\
\text { (hours) }^{\mathrm{a}}\end{array}$ \\
\hline 1 & $€ 2,270$ & 8.097 & $\begin{array}{l}\text { Rejected by journal } 6 \text { days after } \\
\text { initial inquiry. Not submitted }\end{array}$ & 12 \\
\hline 2 & $\begin{array}{c}€ 1,745 \text { or } € 872.50 \\
\text { after a } 50 \% \text { discount }\end{array}$ & $\mathrm{NA}^{\mathrm{b}}$ & $\begin{array}{l}\text { Withdrawn by authors } 7 \text { days } \\
\text { after initial submission because } \\
\text { the article processing charge was } \\
\text { unaffordable }\end{array}$ & 8 \\
\hline 3 & $\begin{array}{l}\text { US } \$ 150 \text { (for a } \\
\text { maximum of } 1000 \\
\text { words), waived on } \\
\text { request }\end{array}$ & $\mathrm{NA}^{\mathrm{c}}$ & $\begin{array}{l}\text { Accepted } 4 \text { days after initial } \\
\text { submission. Version } 1 \text { published } \\
6 \text { days after acceptance. Version } \\
2 \text { (peer-reviewed) published } 27 \\
\text { days after version } 1\end{array}$ & $\begin{array}{l}20(\text { version } 1)^{d} \\
10(\text { version } 2)\end{array}$ \\
\hline
\end{tabular}

a Sum of the time both authors spent deciding where to submit (all three venues), identifying and applying relevant instructions and rules for manuscript category and manuscript format (all three venues), preparing the initial inquiry and deciding how to proceed (venue 1), submitting material online (venues 2 and 3), requesting an APC waiver (venues 2 and 3), revising the manuscript (venues 2 and 3) and reacting to editorial correspondence (all three venues).

b Journal too young to be eligible for an Impact Factor from Clarivate Analytics at the time.

c F1000Research is not defined as a journal but rather as a publishing platform, and does not seek eligibility for an Impact Factor (https:/ f1000research.com/faqs).

${ }^{d}$ Preparation of the list of suggested reviewers and the cover letter (Note) accounted for most of this time. 


\section{Second venue}

Our next choice was Research Integrity and Peer Review, a journal owned by the same publisher as the first, and specialized in topics our manuscript addressed. We duly modified the keywords, revised the abstract and main text slightly by adding information to make our manuscript more relevant for this journal's readership, and made minor changes to bring the manuscript format in line with the journal's instructions for their Commentary section, which allows the publication of comments on articles published elsewhere. We postponed our second try for one month, until after the end-of-year holiday season. An inquiry letter was not required, so in early January 2018 the corresponding author started the submission process via this publisher's online system, Editorial Manager.

Online submission was laborious. When the article processing charge (APC) waiver request was made, the Editorial Manager application suspended the process and advised the corresponding author to await the journal's decision. It was unclear from the on-screen information whether the alreadyuploaded article data and file would be saved or not, but because it was not possible to proceed further, the only option at that point was to exit Editorial Manager - which the corresponding author did in some confusion and not without trepidation.

The decision arrived 5 calendar days later:

Given that you are an independent researcher at present we understand that it would be difficult for you to provide documentation of your lack of funds. As such, I am writing to confirm that we will be able to offer a $50 \%$ discount of the article-processing charge.

This would mean that if your manuscript was accepted you would have to pay a GBP 685.00/USD 1072.50/EUR 872.50 article-processing charge on this article. Since you are based in Spain, you will be charged the price of EUR 872.50*

*Price does not include Administration Charges (for invoices only) or Value Added Tax (for EU authors only - non-UK authors do not need to pay VAT if they can supply a valid VAT number at payment).

We agreed that the discounted APC was unaffordable. We wondered why the decision email mentioned difficulty in providing "documentation of your lack of funds" - a statement implying that the person who made the decision was unprepared to believe that an APC amounting to several hundred euros each would be an onerous out-of-pocket expense for both of us.

We also agreed that appealing for a full waiver was unlikely to result in any further discount, and would only prolong the submission process to no useful end - resulting again in wasted time for us and for the publisher's staff. So we withdrew the manuscript, removing it from the journal's online system 7 days after the submission process was begun. 
At this point we needed to find a publication venue that would be relevant to readers, would be open access, and would not require a large APC. Because our manuscript was written with explicit reference to an article in the literature rather than as an original research or review article, we searched for venues that had published articles on topics related to those discussed by us and the article we commented on.

\section{Third venue}

An article closely related to the one we commented on had been published (Galipeau et al. 2017) earlier on F1000Research, an innovative open-access, open-peer review publishing platform where peer review begins after publication; when two reviewers have approved the manuscript, it is indexed in bibliographic databases. The platform's Editorial Director was among the authors of both the earlier related article and the more recent BMC Medicine article we discussed, so we hoped that F1000Research would give our manuscript a respectful reading (M.E. Kerans, cited in Shashok (2001)).

After examining their article guidelines, instructions for authors and information about APCs, we decided on an appropriate article type (Opinion) and made minor format changes in the manuscript. We removed the text we had added for the second journal and reduced the word count to a maximum of 1000 to make it eligible for the least expensive APC. Before submission, we prepared a short justification of the relevance of our text and brief descriptions of our own expertise, to submit as a Note together with the manuscript. We hoped that this information would help the Editorial Director see the potential interest of our manuscript for readers.

Because F1000Research requires authors to suggest at least five referees, we spent the equivalent of 1.5 working days compiling a list of 12 names in all. To do this, we reviewed earlier publications to identify appropriate candidates, and then located their current affiliations and email addresses together with links to online information about their relevant knowledge and expertise.

Once our manuscript, note and list of reviewers were submitted, things proceeded smoothly (Table 1). The article was quickly accepted, and to our relief the APC was waived. The proof was delivered a few days later, and contained only one minor format error and a few incorrect web links in the References (in addition to a couple of our own errors).

After publication and peer review of version 1, we spent an additional 10 hours following F1000Research's emailed instructions, writing and posting a comment, composing our responses to the two reviewers, and preparing version 2 of our article. Although both reviewers approved version 1, we felt that each of them raised an important point that merited inclusion in the final version. And because of an error in our table, we had planned to prepare a revised version anyway.

The simplicity of post-publication processes at F1000Research made publication of version 2 efficient and straightforward. Only 27 days elapsed between publication of the first version and publication of our revised article. The entire timeline for publication is shown in Table 2. 
Table 2. Publication timeline at F1000Research for Matarese and Shashok (2018)

\begin{tabular}{|c|c|c|c|}
\hline Step & Date (2018) & $\begin{array}{l}\text { Days elapsed from } \\
\text { previous step }\end{array}$ & $\begin{array}{l}\text { Total days elapsed from } \\
\text { initial submission }\end{array}$ \\
\hline $\begin{array}{l}\text { Initial submission with list of } \\
\text { suggested reviewers }\end{array}$ & 15 January & 0 & 0 \\
\hline Acceptance & 19 January & 4 & 4 \\
\hline Proof received v. 1 & 23 January & 4 & 8 \\
\hline Proof delivered v. 1 & 24 January & 1 & 9 \\
\hline Version 1 published & 25 January & 1 & 10 \\
\hline $\begin{array}{l}\text { First reviewer report } \\
\text { received by authors }\end{array}$ & 5 February & 11 & 21 \\
\hline $\begin{array}{l}\text { Second reviewer report } \\
\text { received by authors }\end{array}$ & 12 February & 7 & 28 \\
\hline Version 2 submitted & 19 February & 7 & 35 \\
\hline Proof received v. 2 & 20 February & 1 & 36 \\
\hline Proof delivered v. 2 & 21 February & 1 & 37 \\
\hline Version 2 published & 21 February & 0 & 37 \\
\hline
\end{tabular}

Our F1000Research experience was positive not only because our manuscript was accepted and published promptly and the APC was waived, but also because of their rapid response times and clear email communications. We were also grateful for the human touch: in addition to their automatically generated emails, we received personal emails from the Editorial Director with additional guidance and suggestions. It was reassuring to know that our material had been read by humans, and that decisions were being made transparently and accountably. Although editorial and publication processes at F1000Research differ in some key aspects from those used by traditional journal publishers, the instructions we received by email after each step were clear, courteous, and helpful in enabling us to proceed efficiently.

\section{PPPR: how hard can it be?}

Options for publishing PPPR items can be hard to identify. Unlike research articles and reviews, the terms used to designate other article types vary across venues. Editorial policies for PPPR manuscripts also vary concerning limits on the numbers of words, references, tables and figures. Some journals peer-review these submissions; others do not. In addition, APCs and waiver policies for PPPR manuscripts differ across journals. The guidelines for authors have to be investigated before submission, and it can take time to discover all the rules that apply (Table 1). Our manuscript was prepared first as a Correspondence item, then as a Commentary, then as an Opinion item, and in the 
end it was reclassified by F1000Research as a Correspondence article. Fortunately, adapting our manuscript to the different requirements did not necessitate many format changes along the road to publication, although before submitting the manuscript we needed to spend time verifying the terms and rules at each venue.

Reading, emailing, annotating, drafting, revising, file management and file uploading are tasks that may each last only a few minutes, but that consume substantial amounts of time when added up. For us, the most surprising aspect of our experience was how much time we both needed to comply with the requirements at each venue. As authors' editors we are used to perusing guidelines across a variety of journals and publishers, yet having to comply with them ourselves was an eye-opening experience. For authors whose first language is not English or who are inexperienced with navigating different sets of instructions and guidelines, the PPPR process is probably even more challenging and timeconsuming than it was for us.

Our experience raises questions about PPPR that merit further consideration and debate. Firstly, for articles of this type, how much quality improvement is to be gained in return for the resources expended on peer-reviewing them? Obviously editorial oversight and quality control are required, but the full peer review process for these submissions may be wasteful. Our F1000Research reviewers provided important insights that we were happy to include in our revised version, but this feedback was obtained at the expense of considerable time we invested preparing our list of suggested referees, time our two reviewers spent reading our submission and the article we commented on, and time and resources expended by F1000Research to contact the people we nominated (and in at least one case, to clarify the type of feedback they were seeking).

These editorial resources bring us to our second question: To what degree should journals be required to publish PPPR on articles they have previously published? Despite widespread agreement on the importance of PPPR (Iverson et al. 2009; Moher et al. 2017; https://publicationethics.org/postpublication; http://www.icmje.org/recommendations/browse/ publishing-and-editorial-issues/correspondence.html; http://www.wame.org/policy-statements) journals are under no formal obligation to publish contributions of this nature. Because the journal that published the article we commented on was not interested in our contribution, we were forced to seek publication elsewhere. F1000Research provided a good home for our feedback, but to do this they needed to expend editorial resources that ideally - and perhaps more fairly - should have been expended by BMC Medicine. If PPPR is published in a venue other than the journal where the original article lives, readers may never discover it. This problematic outcome is wasteful for authors of PPPR because it may deprive them of potential readers, and wasteful for readers who must invest additional time and effort to discover and retrieve PPPR on articles they have read.

A third question is how often people with important post-publication feedback are dissuaded from publishing it for reasons similar to those we encountered. Barriers and disincentives to publishing PPPR, as noted by others, include but are not limited to: 
- Stringent limits on length and the number of references, which can make it challenging - if not impossible - for experts to explain the issues clearly and convincingly (Altman 2005; von Elm et al. 2009). As a result, potential post-publication peer reviewers may decide that a letter to the editor is not an efficient way to raise issues that require attention, and may opt to post a comment on PubPeer.com or a blog instead (Saunders 2011).

- Unreasonably short time windows after publication of the original article during which PPPR may be submitted (Altman 2005).

- Possible need to pay an APC (Allison et al. 2016; Mebane and Meyer 2016), a barrier that would have prevented the publication of our article. If an APC for gold open access has to be paid, authors may be reluctant to spend scarce funds to cover publication costs. Moreover, research funders may restrict the use of publication funds to original research articles, systematic reviews and meta-analyses, i.e. "prestigious" article types likely to contribute more to institutional performance indicators.

- Low likelihood that the authors of articles that receive PPPR will reply or act upon the feedback (Markie 2015) or, in cases of invalidating criticisms, that the journal editor will investigate the possibility of retraction (Allison et al. 2016).

A further disincentive for trying to publish PPPR may be the perception (by institutional employees - which we are not) that the time and effort required are not compensated adequately in terms of professional rewards. Writing for publication consumes large chunks of time, especially when English is not the writer's first language (Cameron et al. 2011; Ghanbari and Derakhshan Rad 2015), but the career rewards for publishing a letter, correspondence, commentary or opinion piece may be marginal. In researcher promotion assessments and institutional performance evaluations we are familiar with, priority is given to original outputs such as research articles and systematic reviews. In contrast, correspondence and opinion articles may be excluded from consideration a priori, as already noted for Germany (Stang et al. 2008) and Iran (Ghanbari and Derakhshan Rad 2015), or may be disregarded in assessment exercises that evaluate only a small selection of researchers' best output (e.g. institutional evaluations in France, Italy and UK (Jonkers and Zacharewicz 2016)). We note that in Spain (MECD 2017) and Italy (Mazzoni and Iori 2014; ANVUR 2015), current research evaluation policies discourage biomedical researchers from submitting PPPR publications as evidence of their research output.

For readers, a fourth issue is the lack of cross-platform connectivity between published items and PPPR publications directly arising from them. In 2013 the editors of PLoS Medicine noted that "not many ... secondary articles or posts link back to the original, and in very few cases do articles themselves link out to their post-publication commentary" (PLoS Medicine Editors 2013). The closure of PubMed Commons (NCBI 2018) unfortunately eliminated one effective channel for explicit crosslinking. Winker observed that PPPR publications related to paywalled articles may require payment of an additional pay-per-view fee, and that the "reader who wants a comprehensive view of a research article's PPPR needs time, skill, and patience, not necessarily characteristics of a busy researcher, physician, or patient" (Winker 2015). More challenging still, although equally desirable, is the inclusion of links to blog posts and comments (Tennant 2017). Although our F1000Research article 
cites and links to the original article we commented on, there is no explicit indication in the original article online that it has received subsequent PPPR.

A final question, with implications especially for scholars with limited access to funding for gold open access APCs, is whether it is ethical to require payment to publish feedback offered altruistically to enhance the rigor of available knowledge. Readers may feel motivated to draw attention to potential shortcomings in published articles, or to provide useful supporting evidence. As others have noted, however, they are unlikely to understand why they should pay for the privilege of correcting errors that pre-publication peer reviewers overlooked (Allison et al. 2016; Mebane and Meyer 2016).

\section{Discussion and suggestions}

Widespread agreement on the importance of PPPR is grounded on the view that "real" peer review begins after publication, when the entire community of experts rather than a small, possibly nonrepresentative selection of pre-publication reviewers (Rennie 1998; Jefferson and Shashok 2003) can debate the strengths and weaknesses of published research reports. Although international organizations involved in science publishing support PPPR, journals may not facilitate this type of scientific exchange, and institutions appear not to encourage it.

Journal publishers could do more to facilitate PPPR (as recommended by WAME, the AMA Manual of Style and others mentioned in the Introduction), for example by joining the AAK coalition (https://hypothes.is/annotating-all-knowledge/), or providing a comment service similar to that used by PeerJ (https://peerj.com/about/policies-and-procedures/\#commenting-policies). These measures are important, particularly because post-publication criticism and debate can reassure readers about "the long-term credibility of the scientific record" (Marcus and Oransky 2011). But because letters are not considered citable items by Clarivate Analytics, the company that produces the Journal Impact Factors (JIF; https://clarivate.libguides.com/jcr), editors and publishers may be reluctant to devote human and technical resources to these items since they provide no return on the publisher's investment in terms of a higher JIF. We wonder whether some journals inadvertently - or perhaps intentionally - discourage PPPR submissions by making it needlessly difficult for authors to prepare and submit them, and by making publication contingent upon additional editorial review, reception of a reply from the authors of the original article, or payment of an APC.

Institutions and research evaluation committees could create incentives for greater participation in PPPR by rewarding these knowledge-sharing activities more explicitly. Because research evaluation is closely tied to article metrics and journal citation data, PPPR as a type of publication output may never have the weight of original research or review articles. It could be assessed, however, alongside teaching, thesis mentoring, editorial board membership and conference organizing, as other evidence of achievement (e.g. titoli in MIUR (2016) and aportaciones extraordinarias in MECD (2017)).

If journals derive no benefits from PPPR in terms of ranking or prestige, publishers have little reason to devote resources to essentially unprofitable editorial or production work. If researchers' employers 
and funders do not incentivize or reward PPPR, researchers have little motivation to invest their efforts in this. These circumstances, all of which reduce or eliminate tangible benefits to researchers, institutions and publishers, may thus converge to result in a general lack of motivation for - and consequent temptation to retreat from - publishing PPPR by stakeholders in research communication and knowledge creation.

Research publication is intended to support scientific progress by allowing people to share knowledge, and PPPR is a valuable way to expand discussions on new discoveries. It is used to call readers' attention to errors, provide constructive feedback to authors, and quickly stop faulty but impressivelooking research from gaining credibility among researchers and the public in general (Knoepfler 2015). The intellectual effort devoted to both pre-publication and post-publication peer review, however, goes mostly unrewarded by research evaluators. The lack of career incentives to participate in constructive debate on the merits and limitations of new research is paradoxical given the pressures researchers are under to publish, and the resulting need for peer review both before and, increasingly, after publication (Markie 2015; Tennant 2017). We join those who are now encouraging research evaluators to offer career incentives for scientists who, despite the barriers they may face, succeed in publishing PPPR articles that make important contributions to the body of knowledge - particularly in light of frequent failures of pre-publication peer review to flag important methodological or reporting issues.

In conclusion, the obstacles we hit along the road to publication exemplify how much effort may be needed to publish PPPR comments, and illustrate a few shortcomings in some journals' editorial processes. This case study will, we hope, alert editors and publishers to opportunities for improving their instructions to authors, online manuscript submission systems, and communications with different actors in the publication process to make PPPR easier.

\section{Acknowledgments}

We thank Catherine Mark for insightful feedback and suggestions on the manuscript, and Jon Tennant for useful suggestions that improved an earlier version of the manuscript.

\section{Conflicts of interest}

The authors report no conflicts of interest.

\section{References}

Allison, David B.; Brown, Andrew W.; George, Brandon J. and Kaiser, Kathryn A. (2016) 'Reproducibility: A tragedy of errors', Nature, 530(7588): 27-9. Available at https://www.nature.com/news/reproducibility-a-tragedy-of-errors-1.19264, last accessed 29 July 2018.

Altman, Douglas G. (2005) 'Unjustified restrictions on letters to the editor', PLoS Medicine, 2(5): e126. Available at https://doi.org/10.1371/journal.pmed.0020126, last accessed 29 July 2018. 
ANVUR (2015) 'Evaluation of research quality 2011-2014 (VQR 2011-2014) Call for participation', Rome: Agenzia Nazionale di Valutazione del Sistema Universitario e della Ricerca. Available at http://www.anvur.it/wp-content/uploads/2015/12/Call\%20VQR_2011_2014_11nov_〜.pdf, last accessed 29 July 2018.

Belluz, Julia and Hoffman, Steven (2015) 'Let's stop pretending peer review works', Vox. Posted 7 December 2015. Available at https://www.vox.com/2015/12/7/9865086/peer-review-scienceproblems, last accessed 29 July 2018.

Burrough-Boenisch, Joy (2013) 'Editing non-native English: reflections from a Netherlands-based editor on those who do it and the skills they should have', The 21st Century Text, 13(1). Available at http://21 centurytext.wordpress.com/editing-non-native-english/, last accessed 29 July 2018.

Cameron, Carrie; Chang, Shine and Pagel, Walter (2011) 'Scientific English: a program for addressing linguistic barriers of international research trainees in the United States', Journal of Cancer Education, 26(1): 72-8.

Eastwood, Susan (1981) 'The author's editor in the setting of a university or research center', Journal of Research Communication Studies, 3: 211-6.

Galipeau, James; Cobey, Kelly D.; Barbour, Virginia et al. (2017) 'An international survey and modified Delphi process revealed editors' perceptions, training needs, and ratings of competencyrelated statements for the development of core competencies for scientific editors of biomedical journals [version 1; referees: 2 approved]', F1000Research, 6: 1634. Available at https:/ f1000research.com/articles/6-1634/v1, last accessed 29 July 2018.

Ghanbari, Ali and Derakhshan Rad, Seyed-Alireza (2015) 'Post publication peer review in Iranian biomedical journals', GMR Galen Medical Journal, 4(1): 1-7. Available at www.gmj.ir/index.php/gmj/article/download/180/pdf_58, last accessed 29 July 2018.

Goldacre, Ben (2016) 'JAMA reject correction letters on all trials they have misreported', Compare. Posted 24 March 2016. Available at http://compare-trials.org/blog/jama-reject-all-correctionletters/, last accessed 29 July 2018.

Hames, Irene (2013) 'The future of peer review', EASE/ISMTE Conference, Blankenberge, 23 September 2013. Available at http:/ /www.ease.org.uk/wpcontent/uploads/irene_hames_the_future_of_peer_review_september_2013.pdf, last accessed 29 July 2018.

Huang, Sui (2013) 'When peers are not peers and don't know it: The Dunning-Kruger effect and self-fulfilling prophecy in peer-review', Bioessays, 35: 414-6. Available at https://onlinelibrary.wiley.com/doi/pdf/10.1002/bies.201200182, last accessed 29 July 2018. 
Iverson, Cheryl; Christiansen, Stacy; Flanagin, Annette and American Medical Association (2009) AMA Manual of Style: a guide for authors and editors, 10th edn. New York: Oxford University Press. (section 6.1.9). Available at http://www.amamanualofstyle.com/view/10.1093/jama/9780195176339.001.0001/med9780195176339-div2-248, last accessed 29 July 2018.

Jefferson, Tom and Shashok, Karen (2003) 'Journals: how to decide what's worth publishing (Correspondence)', Nature, 421: 209-10. Available at https://www.nature.com/articles/421209b, last accessed 29 July 2018.

Jonkers, Koen and Zacharewicz, Thomas (2016) Research performance based funding systems: a comparative assessment. EUR $27837 \mathrm{EN}$; doi:10.2791/659483. Available at http://publications.jrc.ec.europa.eu/repository/bitstream/JRC101043/kj1a27837enn.pdf, last accessed 29 July 2018.

Knoepfler, Paul (2015) 'Reviewing post-publication peer review', Trends in Genetics, 31(5): 221-3. Available at https://www.ncbi.nlm.nih.gov/pmc/articles/PMC4472664/, last accessed 29 July 2018.

Liesegang, Thomas J. (2010) 'Peer review should continue after publication', American Journal of Ophthalmology, 149(3): 359-60. Available at http://www.ajo.com/article/S0002-9394(09)008782/ fulltext, last accessed 29 July 2018.

Marcus, Adam and Oransky, Ivan (2011) 'The paper is not sacred (Comment)', Nature, 480: 449-50.

Markie, Michael L. (2015) 'Post-publication peer review, in all its guises, is here to stay', Insights, 28(2): 107-10. Available at https://insights.uksg.org/articles/10.1629/uksg.245/, last accessed 29 July 2018.

Matarese, Valerie (2016) Editing research: the author editing approach to providing effective support to writers of research papers. Medford: Information Today, Inc.

Matarese, Valerie and Shashok Karen (2018) 'Improving the biomedical research literature; how insights from authors' editors can help journal editors define and refine their core competencies. [version 2; referees: 2 approved]', F1000Research, 7: 109 (doi: 10.12688/f1000research.13760.2) Available at https://f1000research.com/articles/7-109/v2, last accessed 29 July 2018.

Mazzoni, Katia and Iori, Rita (2014) Criteri ministeriali per la valutazione della produzione scientifica (pubblicazioni). Reggio Emilia: Biblioteca Medica Corradini. Available at http://biblioteca.asmn.re.it/allegati/Regole\%20MInisteriali\%20IF\%20RC2015\%20\%282014\%29.pd f, last accessed 29 July 2018. 
Mebane, C.A. and Meyer, J.S. (2016) 'Environmental toxicology without chemistry and publication without discourse: Linked impediments to better science', Environmental Toxicology and Chemistry, 35(6): 1335-6.

MECD (2017) Resolución de 23 de noviembre de 2017, de la Comisión Nacional Evaluadora de la Actividad Investigadora, por la que se publican los criterios específicos aprobados para cada uno de los campos de evaluación. Boletín Oficial del Estado núm. 292, de 1 de diciembre de 2017, páginas 117060 a 117080 (21 págs.), Sección: III. Otras disposiciones, Departamento: Ministerio de Educación, Cultura y Deporte. Available at https://www.boe.es/diario_boe/txt.php?id=BOE-A2017-14085, last accessed 29 July 2018.

MIUR (2016) Decreto 7 giugno 2016, n. 120. Regolamento recante criteri e parametri per la valutazione dei candidati ai fini dell'attribuzione dell'abilitazione scientifica nazionale per l'accesso alla prima e alla seconda fascia dei professori universitari... Allegato A. Available at http://www.gazzettaufficiale.it/eli/id/2016/07/05/16G00130/sg, last accessed 29 July 2018.

NCBI (2018) 'PubMed Commons to be discontinued', NCBI Insights. Available at https://ncbiinsights.ncbi.nlm.nih.gov/2018/02/01/pubmed-commons-to-be-discontinued/, last accessed 29 July 2018.

PLOS Medicine Editors (2013) 'Getting closer to a fully correctable and connected research literature', PLoS Medicine. Available at https://doi.org/10.1371/journal.pmed.1001408, last accessed 29 July 2018.

Poole, Charles (1996) 'Invited commentary: Evolution of epidemiologic evidence on magnetic fields and childhood cancers', American Journal of Epidemiology 143(2): 129-32. Available at https://pdfs.semanticscholar.org/be75/6b653f1d8fdbf473f95da03f1c81ce188875.pdf, last accessed 29 July 2018.

Rennie, Drummond (1998) 'Freedom and responsibility in medical publication. Setting the balance right', JAMA, 280(3): 300-2. Available at https://jamanetwork.com/journals/jama/fullarticle/187765, last accessed 29 July 2018.

Ross-Hellauer, Tony (2016) 'Disambiguating post-publication peer review', OpenAIRE blog. Available at https://blogs.openaire.eu/?p=1205, last accessed 29 July 2018.

Saunders, Travis (2011) 'Post-publication peer review: blogs vs letters to the editor', Science of Blogging. Available at https://web.archive.org/web/20110826203612/http://scienceofblogging.com/postpublication-peer-review-blogs-vs-letters-to-the-editor/, last accessed 29 July 2018.

Shashok, Karen (2001) 'Author's editors: facilitators of science information transfer', Learned Publishing, 14(2): 113-21. Available at 
https://onlinelibrary.wiley.com/doi/epdf/10.1087/095315101300059495, last accessed 29 July 2018.

Shashok, Karen (2008) 'Content and communication: How can peer review provide helpful feedback about the writing?’ BMC Medical Research Methodology, 8: 3. Available at https:/ / bmcmedresmethodol.biomedcentral.com/articles/10.1186/1471-2288-8-3, last accessed 29 July 2018.

Smith, Richard (2006) 'Peer review: a flawed process at the heart of science and journals', Journal of the Royal Society of Medicine, 99(4): 17882. Available at https://www.ncbi.nlm.nih.gov/pmc/articles/PMC1420798/, last accessed 29 July 2018.

Smith, Richard (2011) 'What is post publication peer review?' The BMJ Opinion. Available at http://blogs.bmj.com/bmj/2011/04/06/richard-smith-what-is-post-publication-peer-review/, last accessed 29 July 2018.

Stang, Andreas; Poole, Charles and Schmidt-Pokrzywniak, Andrea (2008) 'Pre-peer review, peer review, and post-peer review: three areas with potential for improvement', Journal of Clinical Epidemiology, 61(4): 309-10.

Tacker, Martha M. (1980) 'Author's editors: catalysts of scientific publishing', CBE Views, 3: 3-11.

Tennant, Jon (2017) 'What are the barriers to post-publication peer review?' ScienceOpen Blog. Available at http://blog.scienceopen.com/2017/03/what-are-the-barriers-to-post-publication-peerreview/, last accessed 29 July 2018.

Tennant, Jonathan P.; Dugan, Jonathan M.; Graziotin, Daniel; Jacques, Damien C.; Waldner, François; Mietchen, Daniel; Elkhatib, Yehia; Collister, Lauren B.; Pikas, Christina K.; Crick, Tom; Masuzzo, Paola; Caravaggi, Anthony; Berg, Devin R.; Niemeyer, Kyle E.; Ross-Hellauer, Tony; Mannheimer, Sara; Rigling, Lillian; Katz, Daniel S.; Tzovaras, Bastian Greshake; Pacheco-Mendoza, Josmel; Fatima, Nazeefa; Poblet, Marta; Isaakidis, Marios; Irawan, Dasapta Erwin; Renaut, Sébastien; Madan, Christopher R.; Matthias, Lisa; Kjær, Jesper Nørgaard; O’Donnell, Daniel Paul; Neylon, Cameron; Kearns, Sarah; Selvaraju, Manojkumar and Colomb, Julien (2017) 'A multi-disciplinary perspective on emergent and future innovations in peer review. [version 3; referees: 2 approved]', F1000Research, 6: 1151. Available at https://f1000research.com/articles/6-1151/v3, last accessed 29 July 2018.

von Elm, Erik; Wandel, Simon and Jüni, Peter (2009) 'The role of correspondence sections in postpublication peer review: A bibliometric study of general and internal medicine journals', Scientometrics, 81(3): 747-55. 
Wager, Elizabeth and Jefferson, Tom (2001) 'Shortcomings of peer review in biomedical journals', Learned Publishing, 14(4): 257-63. Available at https://onlinelibrary.wiley.com/doi/pdf/10.1087/095315101753141356, last accessed 29 July 2018.

Winker, Margaret (2015) ${ }^{\circ}$ The promise of post-publication peer review: how do we get there from here?' Learned Publishing, 28(2): 143-5. Available at https://onlinelibrary.wiley.com/doi/epdf/10.1087/20150209, last accessed 29 July 2018. 